Witold Sobczak (D)

Uniwersytet Łódzki witold.sobczak@uni.lodz.pl

\title{
Petr Čermák, Dana Kratochvílová, Olga Nádvorníková and Pavel Štichauer (eds.), \\ Complex Words, Causatives, Verbal Periphrases \\ and The Gerund. Romance languages versus Czech \\ (a parallel corpus-based study), \\ Karolinum Press, 2020, 163 pp.
}

The monograph Complex Words, Causatives, Verbal Periphrases and The Gerund. Romance languages versus Czech (a parallel corpus-based study), edited by Petr Čermák, Dana Kratochvílová, Olga Nádvorníková, Pavel Štichauer, is a book oriented primarily to readers whose mother tongue is not Czech and who might have a primary or secondary interest in this Slavic language. It offers a corpus-based analysis of four research topics (complex words, causatives, verbal periphrases and the gerund) in four Romance languages (Spanish, French, Italian, Portuguese) in the light of their respondents in a typologically different language. The authors provide English translation for Romance examples and concentrate exclusively on crucial differences between the above-mentioned languages, so the reader is not expected to know all of them.

It goes without saying that complex words, causatives, verbal periphrases and the gerund are considered to be phenomena typical of 
Romance languages, and their function in Spanish, Italian, French and Portuguese is largely comparable. Therefore, it seems fully justified to contrast them as a whole with the Czech language. From a contrastive perspective, the purpose of this monograph is to compare the representation of potential (non-volitional) participation, iterativity, causation, ingressivity and adverbial subordination in the Romance languages and in Czech rather than presenting partial analyses devoted exclusively to one of them.

It is worth pointing out that the authors do not focus in this case on the formal manifestation of the phenomena under scrutiny. Rather, they classify the suffix -ble/-bile/-vel, the prefix re-/ri-, the construction hacer/farelfaire/fazer + infinitive, the ingressive periphrasis and the gerund as prototypical or "pure" expression form of abstract categories of potential (non-volitional) participation, iterativity, causativity, the beginning of an action and adverbial (or circumstantial) subordination. By analysing the usage of these categories, the main focus of this work is to explain to what extent they are systematically encoded in Czech and on which language levels they can primarily be found.

The monograph (163 pages) consists of seven chapters and a representative bibliography (pp. 154-163) in which the reader can find publications in Czech, English, French, German, Italian, Spanish and Portuguese. Chapters 3-6 constitute the core of the monograph, where different types of corpus-based analyses are comprehensively presented and illustrated by numerous tables and examples.

Chapter one (pp. 9-14) by Petr Čermák, Dana Kratochvílová, Olga Nádvorníková and Pavel Štichauer delineates a long-term project initiated in 2013 by an investigation group of experienced academic teachers (Petr Čermák, Pavel Štichauer, Jan Hricsina, Jaroslava Jindrová, Zuzana Krinková, Olga Nádvorníková and their PhD (MA, in one case) students (Leontýna Bratánková, Štěpánka Černikovská, Jiří Jančík, Dana Kratochvílová, Petra Laufková, Daniel Petrík and Eliška Tř́šková) from the Department of Romance Studies at the Faculty of Arts of Charles University. The first part of the project was completed in 2015 with the publication of the collective monograph Románské jazyky a čeština ve světle paralelnich korpusů (Karolinum Press). 
Meanwhile, the second phase of the project, in which four members of the original investigation group (Petr Čermák, Dana Kratochvílová, Olga Nádvorníková and Pavel Štichauer) were involved, began in 2018 and finished in 2020, with the final result being the present monograph. Based on the findings of the first phase, the original data and the illustrative examples, the goal of the new book, which has some of the original objectives in common with the first monograph, was to shed new light on the results. Apart from describing the project, in this chapter, the authors also present the objectives and the scope of the monograph, its structure and make some terminological remarks.

In the second chapter (pp. 15-24) Olga Nádvorníková outlines the rigorous methodology of exploiting multilingual corpora by clarifying, among other things, the difference between parallel and comparable corpora. She also draws attention to the structure of a large multilingual (parallel) corpus, InterCorp, created by the Institute of the Czech National Corpus at the same university. Despite having observed some limitations in size and composition of the subcorpora of the InterCorp corpus used to gather the data for the research, Nádvorníková believes that the results obtained in this study are reliable and will be positively verified in future studies.

The third chapter (pp. 25-44), by Pavel Štichauer, Jan Hricsina, Jiří Jančík, Jaroslava Jindrová, Zuzana Krinková and Daniel Petrík, deals with the nature of complex words, more specifically, the suffix -ble/-bile/-vel and the prefix re-/ri-, and it explores the function of these affixes and the representation of these functions in the Czech language. By going deeper into the realm of the lexicon where various unpredictable factors may play a paramount role, the main aim of this chapter is to answer two questions that represent two different typological situations:

1) If, in the target language, Czech in this case, there is a structurally identical word-formation with a more or less similar semantic instruction, can we expect a tendency to adopt a structurally identical solution, i.e. to maintain the same derivational pattern?

2) If there is no structurally analogical word-formation pattern in the target language, or if the pattern is constrained in a completely 
different way, can we nonetheless arrive at a typology of translation solutions, which will tend to be adopted in a quantifiable way?

Chapter four (pp. 45-78) by Petr Čermák, Dana Kratochvílová, Petra Laufková and Pavel Štichauer focuses on the Romance construction hacer/farelfaire/fazer + infinitive utilized as one of the basic tools for denoting causativity in Spanish, Italian, French and Portuguese. Since this notion is defined as a universal category that exists in languages across the whole world, the purpose of this chapter is to compare this category in Romance and Czech. Taking into account the fact that Czech lacks any direct counterpart for the Romance causatives, and considering the inherent fusional nature of this language, the authors endeavour to check whether Czech respondents of the analytic Romance construction are basically fusional or if it is possible to state that Czech causative prefixes are the best translation of hacer/fare/ fairelfazer + infinitive. Based on their detailed analyses, they formulate interesting observations:

1) The analysed constructions display similar combinatory preferences in all four languages, and the Czech respondents do not differ according to the source language.

2) The Czech respondents of the Romance causative construction tend to be heterogeneous and reveal an inherently different organisation of this category is Czech.

The fifth chapter (pp. 79-105), by Dana Kratochvílová, Jaroslava Jindrová, Pavel Štichauer and Eliška Tř́šková, is devoted to presenting the most frequently used verbal periphrases that denote the beginning of a process and their Czech counterparts. To achieve this aim, the authors adopt a new perspective on the abstract notion of ingressivity and present how it can be realised in the Czech language. Given the fact that the chapter deals with a contrastive perspective, the reader has an opportunity to familiarize him or herself with the semantic features expressed by periphrasis regarding two problematic categories in Romance linguistics aspect and Aktionsart. The chapter provides a series of crucial observations regarding fundamental systemic similarities 
between the Romance languages and Czech. For instance, according to the authors of this chapter, "both Czech prefixes and verbo-nominal ingressive constructions display certain combinatory preferences and these limitations are often comparable to those founded with the Romance periphrastic constructions" (p. 103).

When it comes to differences between those languages, Dana Kratochvílová, Jaroslava Jindrová, Pavel Štichauer and Eliška Tř́išková indicate, for example, that "the high frequency cases in which Czech respondents of Romance ingressive constructions did not denote ingressivity at all or lacked any explicit expression of secondary semantic notions attributed to the original periphrasis, which suggest that Czech displays a greater sensitivity to meaning related to the manner of action that are, nevertheless, inherent and contained solely in the semantics of a verb" (p. 105).

In the sixth chapter (pp. 107-146), Olga Nádvorníkova, Leontýna Bratánková, Štěpánka Černikovská and Jan Hricsina analyse the usage of one of the non-finite verbal forms in Romance - the gerund, and its Czech counterpart - the transgressive. In the light of some discrepancies that exist in the valeur of the gerund in the four Romance languages under scrutiny, the authors use as tertium comparationis the cross-linguistic notion of the converb. From the morphological point of view, we deal with two considerably different non-finite verb forms: the Romance gerund, which originates in ablativus gerundii, is non-congruent, "whereas the Czech transgressive agrees with its controller in gender and in number" (p. 144). From the syntactic point of view, "they may be considered the middle member of the scale of the syntactic condensation between the finite verb (in a coordinate or subordinate clause) and nominalisations" (p. 144).

Chapter seven (pp. 147-153), by Petr Čermák, Dana Kratochvílová, Olga Nádvorníková and Pavel Štichauer, presents a series of truly interesting conclusions with respect to five phenomena which can be found in Spanish, French, Italian and Portuguese, such as an expression of potential (non-volitional) participation, repetition (iterativity), causation, the beginning of an action (ingressivity) and adverbial subordination (in the broadest sense of the term). In the Czech language, 
the above-mentioned notions are coded in another way, which means that their prototypical Romance forms of expression do not always have a clear systemic Czech counterpart. Furthermore, in this chapter, the authors present some possibilities for future studies in the area of contrastive corpus-based analysis and the study of abstract linguistic categories and their formal manifestation.

The monograph reviewed here is a very carefully elaborated and coherent corpus-based study both from a methodological and analytical point of view. In my opinion, the book edited by Petr Čermák, Dana Kratochvílová, Olga Nádvorníková and Pavel Štichauer constitutes an important contribution to contrastive studies of Romance and Slavic languages in which the reader finds a series of original and accurate observations regarding their nature. 